\title{
Nutritional status and school eating pattern of adolescents
}

\author{
BHARTI JAIN AND SAKSHI PATHAK
}

Received: 18.01.2016; Revised: 14.05.2016; Accepted: 26.05.2016

See end of the paper for authors' affiliations

\section{BHARTI JAIN}

Department of Food Science and

Nutrition, Maharshi Dayanand

Saraswati University, AJMER

(RAJASTHAN) INDIA

Email : drbhartijain27@rediffmail
ABSTRACT : Diet plays a very important role in growth and development of school going adolescents, during which the development of healthy eating habits is of supreme importance. There is a dual burden of under nutrition and over nutrition in this age-group. Nutritional needs during adolescence are increased because of the increased growth rate and changes in body composition associated with puberty. The dramatic increase in energy and nutrient requirements coincides with other factors that may affect adolescents' food choices and nutrient intake and thus, nutritional status. The present study assessed the nutritional status and Schooleating pattern of adolescents studying in Schools of Chandigarh City. Both quantitative and qualitative methods were used in this study. A quantitative survey was carried out using a pre-tested self-administered structured questionnaire among 280 students from the age group of 13 to 15 years studying in government and private schools of Chandigarh City. Demographic profile of the study participants revealed that, out of total, 30.71 per cent (86) were girls, and 69.29 per cent (194) were boys. Results of anthropometric measurements revealed that overweight, obesity and underweight was seen in 7.9 per cent, 6.4 per cent and 36.8 per cent of adolescents, respectively. Overweight and obesity was seen more in girls (11.6\% and 9.3\%, respectively) as compared to boys ( $7.9 \%$ and $6.9 \%$, respectively). Underweight was more observed in boys (41.2\%) as compared to girls $(29.1 \%)$. Study revealed that majority of adolescents prefers to eat in school canteen even after having their packed lunch. The main reason was the influence of their peer groups. Fast food and aerated beverages were most preferred food items consumed from the school canteen. Increase trend in overweight, obesity and under nutrition in early adolescent was due to the change in dietary pattern and consumption of junk food in school. The factors responsible for this is the quest for independence and acceptance by peers, increased mobility, greater time spent at school and/or work activities, and preoccupation with self-image, contribute to the erratic and unhealthy eating behaviour that are common during adolescence. During adolescence, young people are in a transition period when they gradually take over the responsibility for their own eating habits. Knowledge is one of the factors necessary for a healthy transition of responsibility. The incidence of malnutrition can be reduced through appropriate nutrition education and intervention programs involving adolescents, their parents and teacher in the school.

KEY WORDS: Weight status, Anthropometry, School eating pattern, Unhealthy eating behaviour, Packed lunch

- HOW TO CITE THIS PAPER : Jain, Bharti and Pathak, Sakshi (2016). Nutritional status and school eating pattern of adolescents. Asian J. Home Sci., 11 (1) : 226-231, DOI: 10.15740/HAS/AJHS/11.1/226231. 